\title{
Review Article \\ Recent Developments in the Research of Splat Formation Process in Thermal Spraying
}

\author{
Kun Yang, Min Liu, Kesong Zhou, and Changguang Deng \\ Department of New Materials, Guangdong General Research Institute of Industrial Technology \\ (Guangzhou Research Institute of Non-Ferrous Metals), No. 363 Changxing Road, Tianhe District, Guangzhou 510651, China
}

Correspondence should be addressed to Kun Yang; yangkun20021357@hotmail.com

Received 12 November 2012; Accepted 7 December 2012

Academic Editor: Iwan Kityk

Copyright (C) 2013 Kun Yang et al. This is an open access article distributed under the Creative Commons Attribution License, which permits unrestricted use, distribution, and reproduction in any medium, provided the original work is properly cited.

\begin{abstract}
Thermal spraying is a well-established surface modification technology which has been widely used in industrial applications. As the coating properties were mainly determined by the flattening nature of each splat, much attention has been increasingly paid to the study on the splat formation process of thermal sprayed particles. This paper is concerned with the development in the research of the splat formation process of the individual splat deposited by thermal spraying during the past few decades, including the experimental and numerical simulations up to today; some classical splashing models were also reviewed. As a simulation of the actual thermal spray process, the development of the flattening behavior of free falling droplet has been mentioned as well. On the basis of the current investigation, some recommendations for the future work have been advised.
\end{abstract}

\section{Motivation to Study Splat Formation Process}

"God made the bulk; the surface was invented by the devil" [1]. This comment indicates that the surfaces of parts are the location for many phenomena between the material and its environment, where all physical and chemical interactions and exchanges take place [2]. As most of the material damage and failure start from the surface of the material, beside the so-called nanotechnology, surface modification technology has been quickly developed. This method is a hopeful way to realize the sustainable human society in future, as it enables both high performance and recyclability of the material, through modifying the surface of a material by bringing physical, chemical, or biological characteristics different from the ones originally found on the surface of a material, which have been attracting a great deal of attention from various industries, as they present a way to get an entirely different material performance from the surface of materials merely through surface engineering techniques [3].

In general, thermal spraying is such a typical process that can provide thick coating ranging from $20 \mu \mathrm{m}$ to several millimeters on the substrate. This method has been developed since the early 1910 when Dr. Schoop introduced the technique with a flame as the heat source and molten lead for feedstock materials [4], while both electrical (plasma or arc) or chemical means (combustion flame) were usually used as the source of energy for thermal spraying nowadays.

Using this technology, thick coatings can be deposited on the substrate over a large area at a high deposition rate as compared to other coating processes in a very short time; in addition, almost all kinds of materials feed in powder or wire form can be used as the feedstock, including metals, alloys, ceramics, plastics, cermets, and composites. Accordingly, it has been increasingly applied in various fields. Including mechanics, aeronautics, aerospace, chemistry and oil, electronic, military, automotive, medical, marine, and mining, and their development has continuously increased over the last decade [5-11], for example, typically used as thermal barrier coating, TBCs, in power plants; this method has also been widely used to protect the substrate or remanufacturing of the surface damaged products.

However, the controllability or reliability of the process has not been established yet until today. Hence, the question of how to improve the thermal-spray technology is quite worthwhile for paying more attention to it.

The coatings fabricated by thermal spraying are always built up on the roughen substrate by the impingement of the molten or semimolten particles, which flatten after impact 
and solidify quickly, forming a layer. At the beginning of the coating buildup, particles impact directly onto the substrate. The phenomena occurring at this stage determine the adhesion of the coating to the substrate. Following this, the next layer is deposited on the top of the first one, until a coating of the desired thickness is obtained [12]. As the individual splat is unit cell for the entire coating buildup, the flattening and solidification of the individual particle on the substrate surface is the fundamental process for the coating fabrication. Coating microstructure and corresponding properties, such as porosity and adhesion strength, depend strongly on the flattening nature of each splat [13]. Therefore, it is necessary to make clear of the splat formation mechanism of the thermal sprayed particles to establish the controlling way for the coating fabrication.

Consequently, splat characteristics can be recognized by measuring the in-fight condition and investigating on the final splat shape. The desired splat formation can be obtained by changing the spraying parameters and splat-substrate materials combinations and contact nature. By selecting the optimum conditions, thermal spray process can be controlled effectively.

In general, the deposition process of the sprayed particles can be divided into three steps as illustrated in Figure 1. Firstly, the feedstock material was accelerated and heated by the flame prior to impact onto the substrate, then the molten or half-molten particle with high velocity impacts onto the substrate; following this, the molten particle spreading on the substrate surface was driven by the dynamic impact pressure and inertial of the particle; finally, it solidified on the substrate surface with various shapes.

Although the feedstock powder size used in the spraying is always ranging from several tens to several hundreds micrometers, which might not be indentified with the human eyes, the splat flattening and solidification process should be determined by the joint effects of many factor which will be introduced in Section 2. On the other hand, due to the complex shape of the semimolten particles [14] on rough substrate $[15,16]$, most of the common studies are focused on a smoothed flat surface. According to controlling the spraying parameters and splat-substrate natures, many types of splats can be obtained. The investigation is always focused on two typical types of splats as shown in Figure 2. Splash splat with a center splat surrounded by a ring of fragments or numerous splash fingers connect with the central solidification core as shown in Figure 2(a), and diskshaped splat with only a regular central disk as shown in Figure 2(b) can be commonly obtained on the flat substrate surface under designated conditions.

Various investigations on splat formation process have appeared in the literature during the past few decades, and many theoretical, analytical, and experimental studies have been conducted. However, as the current understandings seem still not applicable for all the splat formation problems, no definitive agreement has been achieved so far. With the purpose to understand the current status of the investigation on the splat formation process and control the actual thermal spraying more efficiency, this paper is devoted to giving an overview on the splat formation problem of the individual

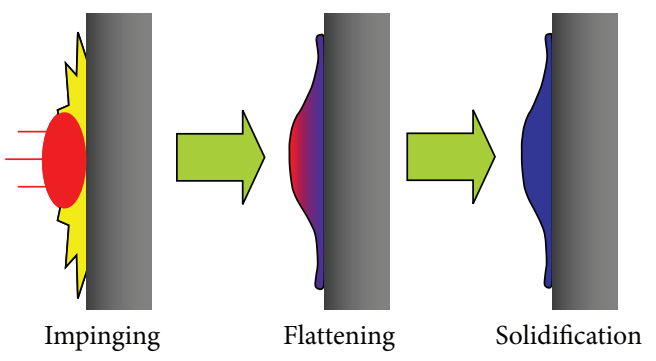

FIGURE 1: Scheme of the splat formation process of a thermal sprayed particle.

splat deposited by thermal spraying. Lastly, the prospect for the future study on this issue is given.

\section{Splat Transition Behavior in Thermal Spraying}

A transition phenomenon in a flattening behavior of the thermal sprayed particle on the flat substrate surface was firstly introduced in 1995 [17], which reported that when the substrate temperature was increased above one critical temperature, the splat shapes of most materials sprayed onto flat substrates underwent a transition from a distorted shape with splash to a disk-shaped splat. The transition temperature, $T_{t}$, as a critical substrate temperature over which more than $50 \%$ of splats are disk shaped, can be considered as a useful tool for the process control.

Figure 3 shows how the fraction of disk-shaped splats varies with the substrate temperature for Ni particles sprayed on an AISI304 stainless steel substrate, and how the transition temperature is defined [13, 17-19]. Actually, most of the feedstock materials sprayed onto the flat substrate exist such a transition behavior through increasing substrate temperature $[22,26-44]$. It is assumed that the adsorption/desorption of adsorbates and condensates on the substrate surface [22, 29-33], surface characteristic change [33-36], and thermal contact resistance $[37,38]$, along with the wetting induced by the topography change might dominate the transition $[45,46]$. It is quite interesting and practically meaningful that the transition in the splat shape of an individual particle corresponds well to the transition in the adhesion strength of the coating fabricated at corresponding temperature conditions $[13,47]$.

On the other hand, controlling the ambient pressure is another convenient way to optimize the actual coating fabrication process. The spraying is conducted in protective environments using vacuum chambers normally back filled with a protective gas at low pressure. This method has been attracting a wide attention because coating particles can be accelerated to much higher speeds without oxidation to metal, and the reaction of the coating materials with plasma operating gases during spraying can be controlled. However, only few attentions have been paid to the splat formation process under reduced pressure conditions. Despite this, existence of a similar transition was indicated recently as indicated in Figure $4[48,49]$, that is, the transition from splash 


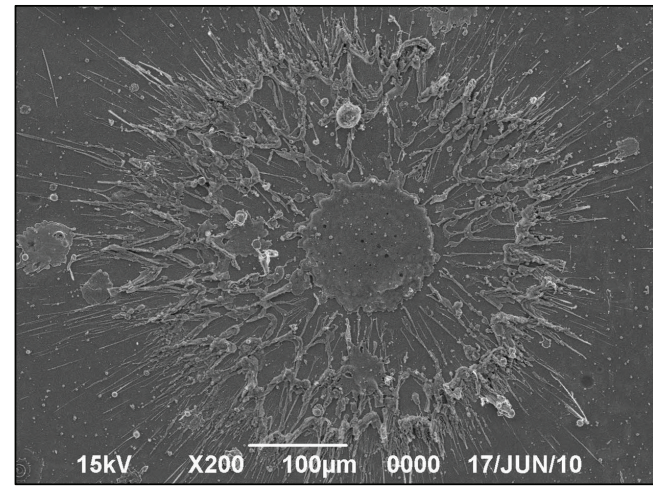

(a)

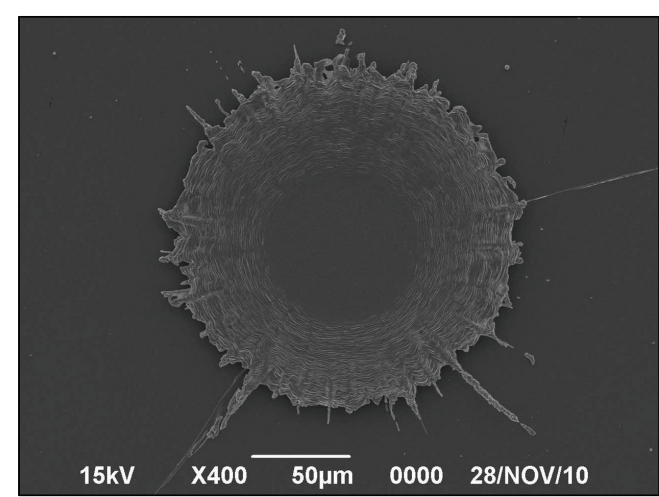

(b)

FIGURE 2: Typical splat morphology: (a) splash splat and (b) disk-shaped splat.

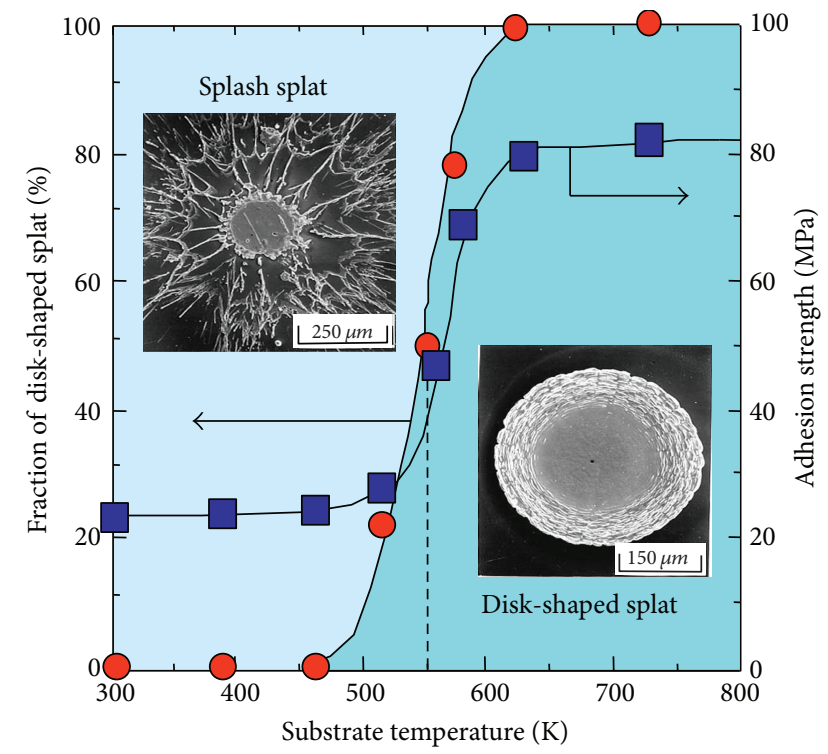

Figure 3: Dependence both of fraction of disk-shaped splat and coating adhesion strength on substrate temperature [13, 17-19].

splat to disk-shaped one occurred by reducing the ambient pressure $[18,20,21,48-51]$. Fukumoto et al. systematically investigated the effect of desorption of adsorbates on particle flattening behavior in low pressure plasma spraying, while the substrate temperature being kept at room temperature $[18,19]$. Transition pressure, $P_{t}$, was defined as the critical ambient pressure at which half of the splats were disk type. The transition pressure is characteristic of the surface: no chemical modification and topography change of the surface occurs when pressure is reduced, and desorption is the only possible physical change taking place. However, it is not fully understood yet. Similarly, the coating adhesion strength has a close relation with the shapes of the depositions through changing ambient pressure [21].

To summarize, splat shapes changed transitionally from splash type to disk-shaped one as increasing substrate temperature or reducing ambient pressure. The coating adhesion

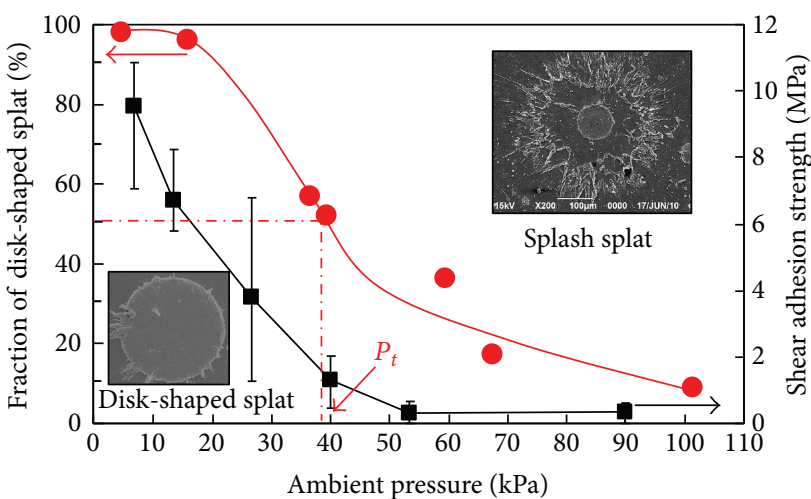

Figure 4: Dependence both of fraction of disk-shaped splat and coating adhesion strength on ambient pressure $[20,21]$.

strength has a close relation with the splat shape. Generally, three different bonding mechanisms involved in thermally sprayed coating: chemical bonding, physical bonding, and mechanical bonding [52-56]. Mechanical bonding usually prevails for most coatings. As the individual splat is the unit cell for the coating buildup, if all the splats adhesive well with the substrate, favorable adhesion strength can be expected for the coatings. On the contrary, poor adhesion strength might exist between the coating and substrate surface. Accordingly, the central disk-like part of the splat should be good adhesive with the substrate, because of that the dynamic impact pressure of the in-flight particle prior to the impinging should be perpendicular to the substrate surface. When the splashing or fragmentation of the splat occurred, the flight direction of the splashing fingers should parallel to the substrate surface, no dynamic pressure might have an effect on the splashing fingers. Hence, few interlocking might be formed. In other words, the existence of splash finger might be the weak point for the adhesive between splat and substrate surface. 


\section{Experimental Investigation on Splat Formation Process}

The initial stage of the splat flattening behavior always focused on the spray parameters [26, 44, 57-60]. A group of spraying parameters were systematically investigated by Li et al. [58]; the splat flattening behavior reveals that the particle's kinetic energy and its molten status are critical in determining the splat morphology. Salimijazi et al. [44] also noted that the in-flight particle temperature and velocity at the point of impact have a significant effect on the final morphology of the splat. On the other hand, the influence of arc current, operating gas flow, and spraying distance on the velocity and temperature of sprayed particles was also measured in the previous study [59, 60]. However, their results proposed that there was no significant change in velocity and temperature with these process parameters.

Instead of the particle oriented factors, feedstock materials on the splat formation process was also evaluated $[27,61-$ 66]; the particle physical properties such as thermal conductivity, surface tension, latent heat, and oxide formation free energy were considered. The influence of substrate materials $[61,67,68]$, in particular, the influence of thermal conductivity for different substrate materials was strongly mentioned. It was found that the smaller the thermal conductivity of the substrate materials, the easier the splat deposited on the substrate as disk-shaped splat. Consequently, the splashing phenomenon was influenced considerably by the initial solidification of the spreading droplet onto flat substrate surface. While for the same substrate material, the state of substrate surface such as oxidation state [26, 27, 39, 69], surface roughness and topography modification through substrate polishing or grit blasting [70-72], heating [33-36, 44, 73], laser treatment $[33,42]$, and micropattern [74-76] was deeply investigated.

For the splat morphology transition phenomena, most studies have focused on the effect of surface roughness or topography change on splat morphology, and little attention was paid to the surface absorbates until Li et al. [22, 77] initially simulated the surface adsorbates/condensates by a prelaid organic substance. They proposed an evaporatedgas model on splat splashing and, as a result, the transition temperature was regarded as creating the desorption process on the surface. In further research by Jiang et al. [31], it was shown that the $\mathrm{ZrO}_{2}$ splat morphology changes progressively with the decrease in the surface adsorbates/condensates content. Fukumoto et al. also proposed the effect of desorption of adsorbates and condensates on the splat collected under reduced ambient pressure $[18,19]$. Meanwhile, Hyland et al. $[52,78-80]$ studied the role of surface chemistry on the splat formation process by the immersion of the substrate in boiling water to grow specific types of oxide/oxyhydroxide on the surface. Their results suggested that the splat morphology was more strongly influenced by water release from the dehydration of oxyhydroxide to oxide than by the simple presence of the oxide layer on the substrate surface.

It has been proposed that the wetting of droplet to substrate surface may have an effect on the droplet flattening $[18,19,26,27,33,45,46,62,81,82]$. The degree of wetting is always described by the contact angle $(\theta)$ at which the liquidvapor interface meets the solid-liquid interface [83]. The contact property of the splat with substrate surface strongly depends on the wetting of the liquid metal to the solid substrate; Suganuma reported that the standard energy of formation of the oxide layer from the metal can be closely related to the wetting of the molten metal on the oxide substrate [84], while the wetting of a liquid metal relative to a solid oxide depends on the thermodynamics of the oxide material; that is, the more thermodynamically unstable the oxide, the easier the wetting [85], which may affect strongly the splat formation process.

Numerous observations have been conducted through changing spraying parameters and powder/substrate combinations. However, thermal spraying is a complex and shortperiod process; it is difficult to clarify the flattening behavior of the thermal sprayed particles directly with preventing technology. Most of the previous investigations were carried out by observing the geometry shape of the splat but without knowing the actual flattening and solidification process, because of the difficulties in performing high resolution studies of the splat-substrate interface. To overcome this difficulty, the pore and grain distribution at cross-section of the individual splat was observed by the assistance of focus ion beam (FIB) and transmission electron microscopy (TEM) [12, 52, 86-90]. The results proposed that different microstructures could be found under designated conditions, the substrate chemistry, roughness, and temperature all play an important role in the splat formation process, but the substrate temperature effect is the most prominent of these.

\section{Numerical Modeling on Splat Formation Process}

In the actual thermal spraying process, the diameters of the feedstock powders were always within several tens micrometers, while the splat flattening and solidification finished in a very short time in several microseconds order. It is very difficult to observe the splat formation process with the prevailing technology. Instead, some numerical models have been carried out extensively for verifying the possible influencing factors on the splat formation process $[38,80,91-$ 105].

The first numerical model of a liquid drop splashing onto a flat surface was proposed by Harlow and Shannon [92]. The full Navier-Stocks equations were solved in cylindrical coordinates in order to investigate the splash of a liquid drop onto a flat plate. The model was mainly applicable for the early stage of droplet impact when kinetic energy was dominant, because the effects of surface tension and viscosity were neglected to simplify the model. Another simple model using a simple model of two-dimensional radial flow of a spherical droplet was proposed by Madejski [93]. More physical characteristics of the droplet were considered in his model; the degree of flattening of a droplet depended upon the Weber, Reynolds, and Peclet numbers, and upon the freezing constant. 
Since then, more and more scientists focused on the numerical simulation to investigate the splat flattening and solidification process. Firstly, Sobolev and Guilemany [94100] theoretically studied the effects of many factors on splat flattening and solidification. Their theoretical results agree well with the experimental observations. A splat formation model has been developed based on the classic nucleation theory accounting for heterogeneous nucleation kinetic and crystal growth to predict the nucleation temperature and grain size distribution [101], the influence of the substrate material, interfacial thermal contact resistance, and wettability on the nucleation, grain size distribution, and rapid solidification process has been investigated. Another integrated model for the interaction between melt flow and nonequilibrium solidification in thermal spraying was developed by Wang et al. [102]. The effects of velocity profiles, droplet size, initial substrate and droplet temperature, and initial impinging velocity on rapid solidification have been investigated. In order to clarify the micropore formation mechanism, a theoretical model was proposed by H. Fukanuma [103], his study indicated that the impinging velocity, the ambient gas pressure, the particle diameter, and the molten material viscosity contribute to producing porosity.

In recent years, $3 \mathrm{D}$ mathematical models of acceleration, heating, and deformation of the particles have been developed to predict the particle transport and splatting on impact with a flat substrate were discussed. A 3D model for the splatting of high-velocity oxyfuel (HVOF) sprayed polymer particles on rough surfaces has been also developed recently [106]; the results indicated that an increase in the magnitude of the mean substrate roughness promoted splat instability and formation of radial fingers, while an increase in general surface roughness may result in a lower spreading ratio of thermally sprayed polymer particles. Three-dimensional molecular dynamics simulation with considering the influence of the impact parameters to clarify at an atomic level the flattening process of a high-temperature droplet impacting a substrate at high speed [104], the flattening ratio increases in proportion to the droplet velocity and the droplet diameter in their study. In addition, the deposition behavior of sprayed particles on inclined substrate was also numerically studied [105].

\section{Splashing Models for Thermal Sprayed Particles}

The splashing phenomenon is frequently found during thermal spraying process. As reviewed above, in order to verify the mechanism of splashing occurrence of splat deposited on flat substrate, much attention has been increasingly paid in the past few decades. Some classical splashing models have been reported up to date; however, they still have not been fully agreed yet.

5.1. Adsorbed Gas Induced Splashing Model. One of the most widely mentioned models proposed is evaporated-gasinduced splashing model as proposed in Figure 5 [22]. The substrate surface is covered with several physical adsorbed condensates prior to the droplet impact onto the flat substrate, the most common condensate on which is water from moisture [22, 31]. Once the molten droplet was thermally sprayed onto the substrate, desorption of adsorbed water on the substrate surface occurred to form a gas barrier between the splat and substrate due to the intensively rapid heating of the substrate surface $[30,107]$. The adsorbed gas induced pressure increased rapidly with the progress of splat flattening process, while the dynamic impact pressure spread out and dissipated quickly with splat flattening. Once the gas-induced pressure became larger than the impact pressure, the flowing fluid would be pushed up or thrown away in jetting by inertial of flowing fluid [22] and deposited as splash splat with a core central zone surrounded by the ring of debris.

However, some phenomena still cannot be explained by this assumption. For example, when the substrate was preheated up to one critical temperature, most of the adsorbed gas condensation has been removed completely [32, 108], with the continuing increase of substrate temperature above this critical temperature, there might be no significant change of surface adsorbates, while the initial dynamic impact pressure is a constant value due to the no change of spraying parameters; however, more and more disk-shaped splats deposited on the substrate surface instead of splash ones with higher temperature, so how does the transition of splat shape occur? Furthermore, even when the substrate was kept at a constant temperature, that is to say, there was no adsorption/desorption change on the substrate surface, different splat morphologies were obtained through changing the powder materials [61-64]. Therefore, some new criterions should have an effect on the splat formation.

5.2. Substrate Melting-Induced Splashing Model. As proposed by the previous researchers, thermal sprayed coating was always mechanical bonded with the substrate [52-56]; however, the substrate melting at the splat-substrate interface during splat collection process was also reported recently with both experimental and numerical simulation [23, 78, 101, 109-113].

Li et al. [23] reported that impacting of a molten droplet with a melting point much higher than the substrate resulted in melting of the substrate around the impact area, which might induce the splashing occurrence. Kitahara and Hasui [109] reported that substrate melting occurred when nickel, chromium, molybdenum, and tungsten were plasma-sprayed onto aluminum and mild steel substrates. Steffens et al. [110] indicated that substrate melting strongly depended on the droplet thermophysical properties, contact temperature, and solidification time. Increasing the substrate or droplet temperature or spraying on a substrate with a low value of thermal conductivity enhanced the degree of melting. Zhang et al. [101] also detected an intermetallic layer between the molybdenum splat and the mild steel substrate and suggested that substrate melting occurred. Melting of the substrate, along with intermixing and diffusion between substrate and splat materials, was found when the nickel-chromium powder was thermally sprayed onto the flat stainless steel 304 substrate, but not for the aluminum substrate [78, 111-113]. 


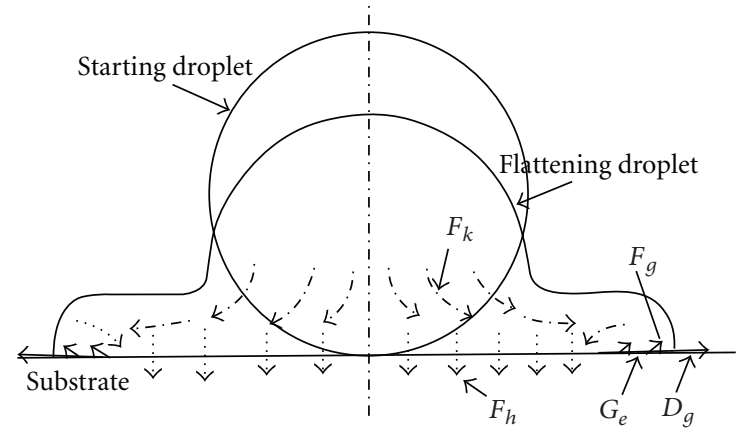

(a)

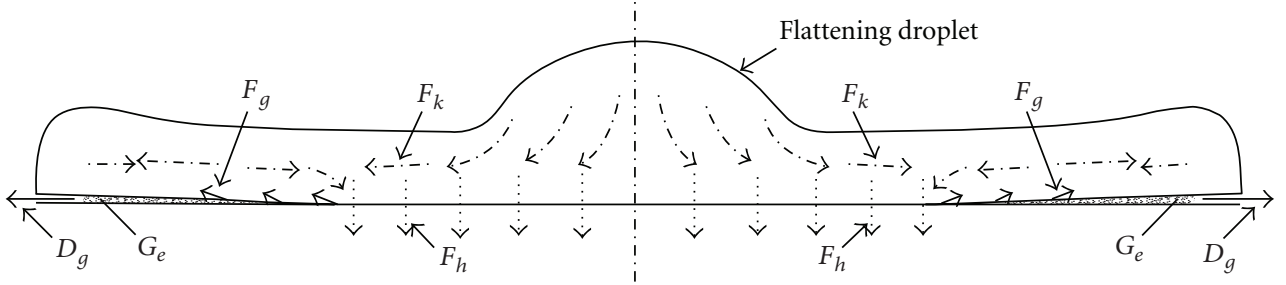

(b)

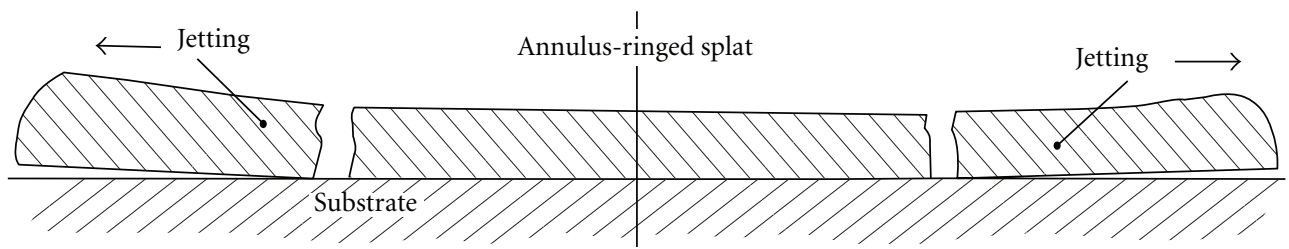

(c)

FIGURE 5: Evaporated-gas-induced splashing model [22]. (a) The early stage of flattening droplet; (b) formation of gas cushion and escape of the accumulated gas, $(c)$ formation of fluid jetting. $F_{k}:$ kinetic energy driven flow; $F_{g}:$ evaporated gas driven flow; $F_{h}:$ heat flow; $G_{e}:$ evaporated gas; $D_{g}$ : gas escape direction.

Substrate melting-induced splashing was reported by Li et al., on the basis of experimental observation as indicated in Figure 6 [23]. It was proposed that once the melting point of a molten droplet was much higher than the substrate, the substrate surface temperature would rise continuously due to the heat transfer from molten droplet to cold substrate, which would cause local melting of the substrate around the impact area. Due to a high dynamic pressure of the inflight prior to the impinging, the melted substrate material would be extruded to flow along the solid surface below the liquid droplet, resulting in the formation of a crater around the impact point. The significant change of fluid flow direction led to the detaching of fluid from the substrate. When the dynamic pressure downward was not high enough to suppress the detachment of the fluid from the solid surface as the crater became large, the ejection of fluid occurred owing to the kinetic inertia of the flowing liquid. This led to the ejecting of droplet material in the form of splashing.
5.3. $K$ Model. The Sommerfeld number, $K$, based on the study of water and ethanol droplet, has been often mentioned recently $[114,115]$, which was described as the following equations:

$$
\begin{gathered}
K=\mathrm{We}^{1 / 2} \operatorname{Re}^{1 / 4}, \\
\mathrm{We}=\frac{\rho d v^{2}}{\gamma}, \\
\operatorname{Re}=\frac{\rho d v}{\eta} .
\end{gathered}
$$

We and Re were the Weber and Reynolds number. Here, $\rho\left(\mathrm{kg} \cdot \mathrm{m}^{-3}\right)$ is the droplet density; $d(\mathrm{~m})$ is the droplet diameter; $v\left(\mathrm{~m} \cdot \mathrm{s}^{-1}\right)$ is the mean droplet velocity; $\gamma\left(\mathrm{N} \cdot \mathrm{s} \cdot \mathrm{m}^{-2}\right)$ is dynamic viscosity of the droplet; $\eta\left(\mathrm{N} \cdot \mathrm{m}^{-1}\right)$ is the surface tension of the droplet, respectively. 


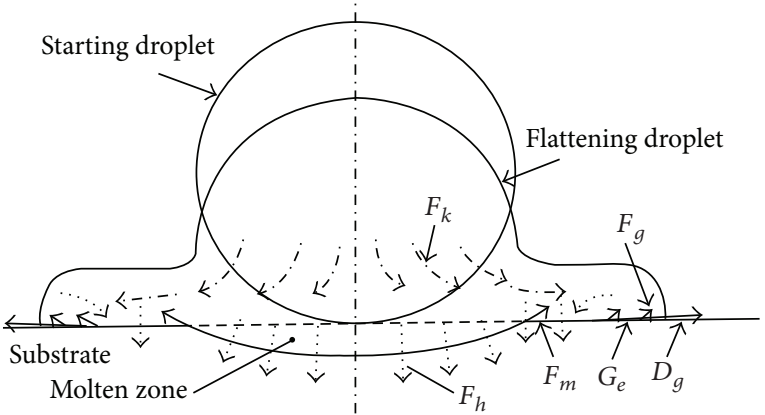

(a)

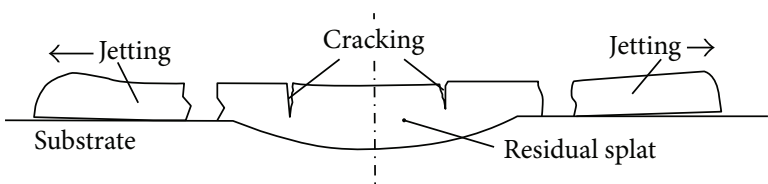

(c)

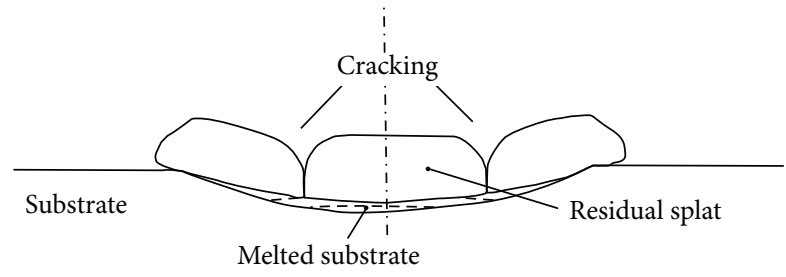

(e)

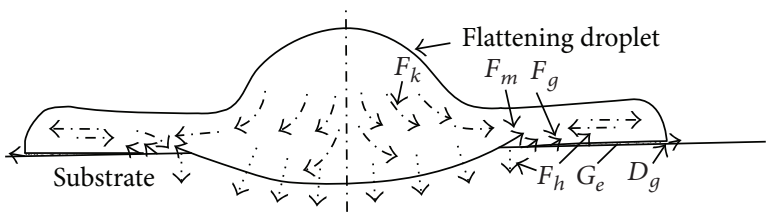

(b)

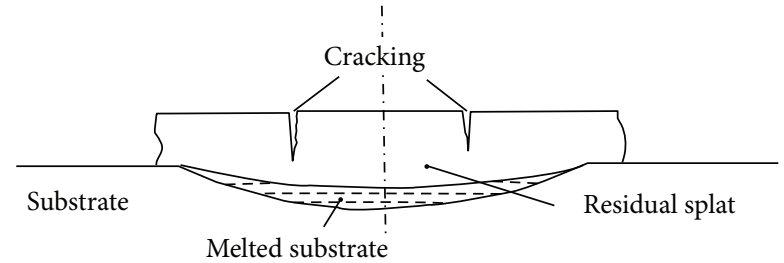

(d)

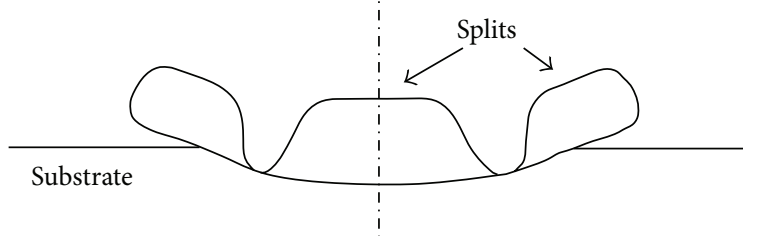

(f)

FIGURE 6: Substrate melting-induced splashing model [23]. $F_{k}$ indicates the flow direction of the spreading fluid driven by kinetic energy. $F_{h}$ is the heat transfer direction from the droplet to the substrate. (a) and (b) indicate the early stages of flattening, resulting in the melting of the substrate by the impacting droplet. $F_{m}$ indicates the flow direction of the spreading fluid resulting from the crater, which is formed by the melted substrate surface region. $F_{g}$ indicates the direction of the evaporated gas-induced force. When flattening completes $(c)$, the splashing occurs, driven by the inertial force of the rapidly flowing fluid along direction $F_{m}$. Cracking occurs as the surface layer of the splat is solidified, as shown in (c) and (d). The displacement by floating of the cracked splits on low-melting-point liquid film results in the formation of splitting of the residual central splat (e) and the final splat (f).

The criteria for describing the nonsolidified liquid droplet on flat substrate surface were defined as [114]

$$
\begin{aligned}
& \text { if } K<3 \text {, splat rebounds; } \\
& \text { if } 3<K<57.7 \text {, it results in deposition; } \\
& \text { if } K>57.7 \text {, it induces splashing. }
\end{aligned}
$$

Therefore, the value of 57.7 could be treated as the critical value as $K_{c}$ the predict the splashing occurrence or not. The $K$ value of thermal sprayed particles can be precisely calculated through first measuring the particle temperature and velocity, and then introducing the measured temperature and velocity into each physical constant, such as density, viscosity, and surface tension. On the basis of the calculation, these critical values seem not applicable for actual thermal spraying conditions under some experimental conditions. These $K$ values are significantly larger than that of $K_{c}$ regardless of the particle size, or the spray distance $[18,19]$. That is to say, regular sprayed particle has enough driving force for the splashing. However, the disk-shaped splat always appeared on the hot substrate, or the lowered ambient pressure in the actual thermal spraying. Escure et al. also proposed that, significant splashing occurred even if the $K$ was smaller than the critical value of 57.7 when alumina particles were thermally sprayed onto the stainless steel substrate [116]. While in Li's study, nearly all the plasma sprayed particles yielded a $K$ from several hundreds to thousands, which was quite higher than the critical value, but the splats deposited by those particles on preheated substrate always displayed a disk shape without any splashing [117].

Actually, the $K$ model is independent of the particle properties. However, some of the transitional change in splat morphology under designated conditions cannot be explained by the traditional $K$. The splat transition phenomenon was reportedly realized just through controlling substrate conditions with no change of the in-flight particles. Consequently, a new independent criterion for splashing, the splashing parameter on flattening $K_{f}$, was defined by 


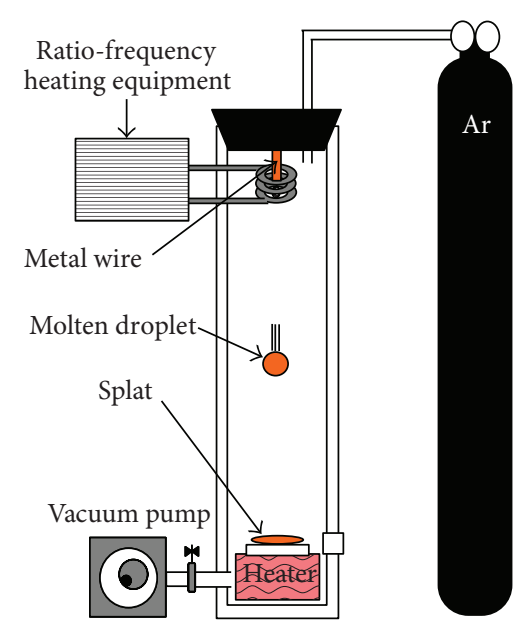

Figure 7: Scheme of free falling experimental apparatus [24].

Fukumoto et al. [24, 59, 118], by integrating the substrate temperature effect and the particle conditions:

$$
K_{f}=0.5 a^{1.25} \mathrm{Re}^{-0.3} K
$$

Here, $a$ is defined as the ratio of the maximum flattening velocity to the impact velocity of the particle and it is influenced by the substrate temperature. However, the detailed physical meaning of the above expression is still not clearly defined.

5.4. Solidification Parameter Model. A splat shape predicting model was proposed by Dhiman and Chandra et al. [40, 53, 119]. The solidification parameter () which was defined as the ratio of the solid layer thickness to splat thickness was used to predict the splat morphology in a thermal spray process as illustrated in the following:

$$
\Theta=\frac{s}{h}=\frac{s / D_{0}}{h / D_{0}}=\frac{s^{*}}{h^{*}}
$$

Here, $D_{0}$ : droplet diameter before impact; $h$ : splat thickness; $h^{*}$ : dimensionless splat thickness $\left(=h / D_{0}\right) ; s$ : thickness of droplet's solidified layer; $s^{*}$ : dimensionless solid layer thickness $\left(=s / D_{0}\right)$.

The criteria for predicting the final splat shape of thermal sprayed particles on flat substrate surface were defined as follows:

(1) If the solid layer is very thin $(s \ll h$, or $\Theta \ll 1)$, which might has no effect on spreading, the splat would spread into a thin sheet liquid and rupture internally.

(2) Once the solid layer grows by a significant amount during spreading $(s \sim 0.1 h$ to $0.3 h$, or $h \sim 0.1-0.3)$, it would restrain the splat from spreading too far and becoming thin enough to rupture. In this case, a diskshaped splat will be produced.

(3) If the solidification is very rapid $(s \sim h$ or $\Theta \sim 1)$, the solid layer will obstruct the outward spreading liquid.

\section{Development in Research of Free Falling Droplet}

Recently, free falling experiments, in which a metal droplet fell freely and impinged on a flat substrate, was conducted to simulate the thermal spray process $[24,25,37,37,120-125]$. Figure 7 shows the schematic of the experimental apparatus [24], in which millimeter-sized metallic droplet was heated and melted by radio-frequency heating equipment prior to the falling, the substrate temperature and ambient pressure can be controlled.

Fukumoto et al. observed the final shapes of the free falling $\mathrm{Cu}$ droplet collected on AISI304 substrate through controlling substrate temperature and ambient pressure. The droplet shapes were summarized in Figure 8 [25]. In their experiment, the chamber pressure was kept at atmospheric pressure when varied the substrate temperature, while no substrate heating was conducted when varied the ambient pressure. From the figure, the droplet shapes changed transitionally from splash type to disk-shaped one both by increasing substrate and reducing ambient pressure. In other words, the droplet shape has a similar transition tendency with the thermal spraying process. Accordingly, the investigation on the flattening behavior of thermal sprayed particles through observation on the free falling droplet should be reasonable and meaningful. The relating factors, such as thermal contact resistance and the droplet velocity at impact, were investigated carefully. According to their studies, the thermal contact resistance was determined by the area of contact between the molten droplet and rough solid substrate [120]. Furthermore, the number of fingers formed around the droplet increased with impact velocity $[120,121]$.

Thermal history at droplet-substrate interface during the droplet spreading and solidification process was proposed in the recent literature. A hole was drilled at the center of substrate, and through this hole, J-type thermocouple was inserted. The thermo-electromotive force was converted to digital signal and recorded by a data logging system [37, 122, 123]. Fukumoto et al. measured the interface temperatures varied with spreading time after the molten droplet impacted onto the flat substrate, and experimentally controlled the dominations of both substrate temperature and ambient pressure $[49,123]$. Their results indicated that the substrate temperature and ambient pressure had an equivalent effect on the solidification rate of the spreading droplet and that faster solidification could be achieved on the substrate holding at high temperature and/or locating under reduced ambient pressure. Similar results had been proposed when some kinds of micrometer-sized particles were thermally sprayed onto flat substrate surfaces [30, 37-39]. In a word, the cooling rule of the droplet is opposite to the theory of Newtonian cooling [126], but the mechanism is still not clear at this moment.

\section{Prospect for the Future Study}

Although various works on the splat formation process have been investigated during the past few decades, some of the splat formation mechanisms are still not clarified. The key 


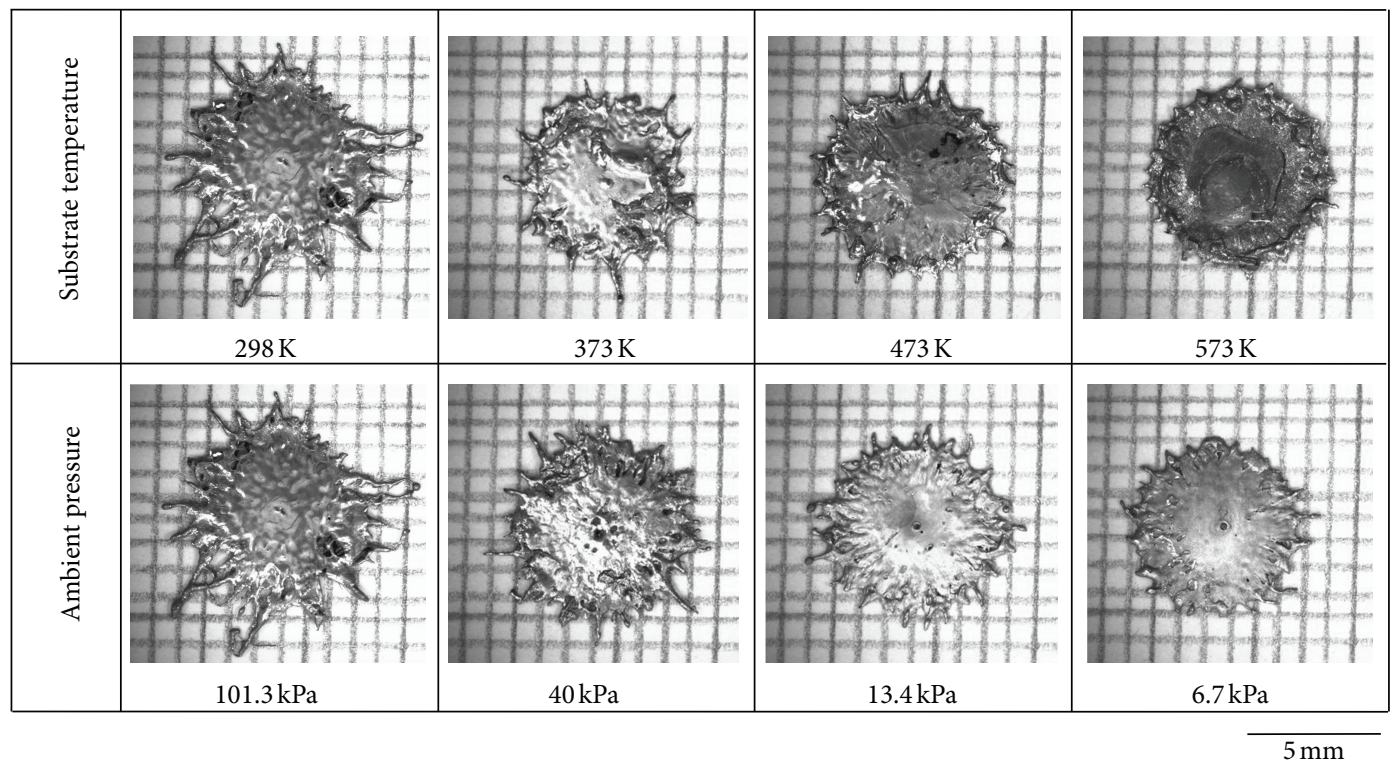

FIGURE 8: Dependence of splat morphologies on the substrate temperature and ambient pressure in the deposition chamber [25].

issues to be answered include why or how does the diskshaped splat appear instead of splashing occurrence and what is the essential of the flattening problem? The author advises that continuing efforts should be devoted to making a deeper understanding on the splat formation process.

(1) Lots of observations on the splat morphologies, for example, the splat geometry shapes and pore distributions, have been widely conducted. However, it is still necessary to characterize the splat-substrate interface at high resolution. Thus, transmission electron microscope (TEM) is advised to observe the solidification structure at the interface in more detail after cutting by focus ion beam (FIB). In particular, the difference of the structures between disk-shaped splat and splash splat collected under designations should be compared systematically.

(2) As the splat formation process always finishes in several to several tens microseconds, and the feedstock size is about only several tens micrometers, it is quite difficult to observe the splat formation process directly with the prevailing technology; thus, a numerical simulation has been widely employed to clarify the flattening and solidification process. However, not enough efforts through controlling ambient pressure have been carried out yet. Therefore, some contributions to this aspect are strongly recommended.

(3) The role of wetting on the flattening behavior of thermal sprayed particles has been proposed in some literature, but most of the studies were focused on the static wetting, which was a thermal equilibrium process and dominated by the surface energy of the molten droplet. During the actual splat formation process, the splat boundary was in motion until the flattening finished, so it is dynamic wetting of substrate by molten droplet. Does the dynamic wetting have an effect on the splat formation process in only several microseconds? If so, how does the dynamic wetting affect the splat flattening process?

(4) Equivalent transition behavior of the splat geometry shaping from splash to disk-shaped ones was found through both increasing substrate temperature and reducing ambient pressure; nevertheless, there existed different microstructure and solidification behaviors. Consequently, it is quite necessary to make clear what the dominant factors in different experimental designations are.

(5) Much attention has been paid to the flattening behavior of thermal sprayed particles under reduced ambient pressure. However, it is quite difficult to get enough coarse depositions under low pressure conditions. Is this a technical problem or do any special phenomena occur? One assumption is that complete fragmentations occur once the molten droplet impacts onto flat substrate surface and that the fragmentations are deposited as smaller diskshaped splats. However, no such deposition process can be proved through observing the final splat shape. Consequently, some technical improvements to collect more splats under reduced ambient pressure should be conducted, and more attention should be paid to the impinging behavior under low pressure designations.

(6) Free falling experiment was proved as a useful method to simulate the actual thermal spraying process. The previous results indicated that the flattening pattern of the molten droplet was decided just after collision onto solid surface, which was earlier enough to 
finalization of the flattening. But we cannot explain how they decide so quickly? And how the influencing factors affect this decision? Therefore, intensive research is needed.

(7) Coatings are built up from the individual particles deposited on the substrate or the previous deposited splat; therefore, the study of splat formation process was not only from the point of view of scientific interest, but also from that of technical consequences as well. Consequently, the investigation on the splat problem should be concerned on the materials with industrial background, for example, materials for new generation thermal barrier coatings (TBCs) and wear coatings.

(8) Coating properties depend strongly on the single splat shape, because the individual splat is the unit cell for the coating buildup, but the previous study was mainly focused on the adhesion strength between the coating and substrate. The coating adhesion is the most fundamental characteristic for the entire coating, a coating will never protect a substrate if it does not adhere to it; however, the dependence of the other coating properties on splat shape should be paid a special attention to.

\section{Summary}

With the purpose to understand the research development of the splat formation process in thermal spraying, this paper reviewed the investigation activities on this aspect during the past few decades, the transition behavior of splat shape changing from splash type to disk-shaped one through controlling substrate temperature or ambient pressure, and the contributions of experimental and numerical modeling to the splat formation process, followed by the review of some classical splashing models. The research development of free falling experiment was also mentioned. Although numerous literature has been published, there are still some problems to be answered on this issue. The intensive research for this issue is still needed.

\section{Acknowledgments}

K. Yang would like to acknowledge Professor Fukumoto Masahiro (Toyohashi University of Technology, Japan) for the opportunity to study in his laboratory and for his assistance and discussions throughout the period of this work. This paper was partially supported both by the National Program on Key Basic Research Project (973 Program, 2012CB625100) and by a Grant from the Ph.D. Programs Foundation of Guangzhou Research Institute of Nonferrous Metals.

\section{References}

[1] U. Hofer, "Self-trapping of electrons at surfaces," Science, vol. 279, no. 5348, pp. 190-191, 1998.
[2] M. Cardon, "How (proper) blast cleaning averted a naval conflict," The Shot Peening, vol. 20, no. 2, p. 38, 2006.

[3] Y. Arata, "Advanced new technology for thermal spray," in Proceedings of the International Symposium on Advanced Thermal Spraying Technology and Allied Coatings, pp. 1-8, Osaka, Japan, 1988.

[4] P. Fauchais, A. Vardelle, and B. Dussoubs, "Quo Vadis thermal spraying?" Journal of Thermal Spray Technology, vol. 10, no. 1, pp. 44-66, 2001.

[5] R. A. Miller, "Current status of thermal barrier coatings-an overview," Surface and Coatings Technology, vol. 30, no. 1, pp. $1-11,1987$.

[6] G. Barbezat, "Advanced thermal spray technology and coating for lightweight engine blocks for the automotive industry," Surface and Coatings Technology, vol. 200, no. 5-6, pp. 1990-1993, 2005.

[7] J. Matějíček, P. Chráska, and J. Linke, “Thermal spray coatings for fusion applications-review," Journal of Thermal Spray Technology, vol. 16, no. 1, pp. 64-83, 2007.

[8] M. L. Thorpe, “Thermal spray. Industry in transition," Advanced Materials and Processes, vol. 143, no. 5, pp. 50-61, 1993.

[9] F. Kassabji, G. Jacq, and J. P. Durand, “Thermal spray application for the next millennium a business development perspective," in Proceedings of the 15th International Thermal Spray Conference, pp. 1677-1680, May 1998.

[10] M. Ducos and J. P. Durand, "Thermal coatings in Europe: a business prospective," in Proceedings of the International Thremal Spray Conferences, pp. 1267-1271, May 2001.

[11] M. Fukumoto, S. Y. Hwang, C. J. Li, K. Tani A, Nakahira, and M. K. A. Khor, "The current status of thermal spraying in Asia," Journal of Thermal Spray Technology, vol. 17, no. 1, pp. 5-13, 2008.

[12] G. Bolelli, K. Sabiruddin, L. Lusvarghi, E. Gualtieri, S. Valeri, and P. P. Bandyopadhyay, "FIB assisted study of plasma sprayed splat-substrate interfaces: NiAl-stainless steel and aluminaNiAl combinations," Surface and Coatings Technology, vol. 205, no. 2, pp. 363-371, 2010.

[13] M. Fukumoto, H. Hayashi, and T. Yokoyama, "Relationship between particle's splat pattern and coating adhesive strength of HVOF sprayed Cu-alloy," Journal of Japan Thermal Spraying Society, vol. 2, no. 3, pp. 149-156, 1995.

[14] H. Ageorges and P. Fauchais, "Plasma spraying of stainless-steel particles coated with an alumina shell," Thin Solid Films, vol. 370, no. 1, pp. 213-222, 2000.

[15] P. Fauchais, M. Vardell, A. Vardell, and L. Bianchi, "Plasma spray: study of the coating generation," Ceramics International, vol. 22, no. 4, pp. 295-303, 1996.

[16] P. Fauchais, M. Vardell, A. Vardell, L. Bianchi, and A. C. Leger, "Parameters controlling the generation and properties of plasma sprayed zirconia coatings," Plasma Chemistry and Plasma Processing, vol. 16, no. 1, pp. s99-s125, 1996.

[17] M. Fukumoto, S. Katoh, and I. Okane, "Splat behavior of plasma sprayed particles on flat substrate surface," in Proceedings of the 14th International Thermal Spray Conference, pp. 353-358, 1995.

[18] M. Fukumoto, M. Shiiba, H. Kaji, and T. Yasui, "Threedimensional transition map of flattening behavior in the thermal spray process," Pure and Applied Chemistry, vol. 77, no. 2, pp. 429-442, 2005.

[19] M. Fukumoto, Y. Tanaka, and E. Nishioka, "Flattening problem of thermal sprayed particles," Materials Science Forum, vol. 449-452, no. 2, pp. 1309-1312, 2004. 
[20] S. Sampath and H. Herman, "Rapid solidification and microstructure development during plasma spray deposition," Journal of Thermal Spray Technology, vol. 5, no. 4, pp. 445-456, 1996.

[21] M. Fukumoto, K. Yang, M. Yamada, and T. Yasui, "Splat formation mechanism in thermal spraying," Journal of Solid Mechanics and Material Engineering, vol. 5, no. 12, pp. 1001-1014, 2011.

[22] C. J. Li and J. L. Li, "Evaporated-gas-induced splashing model for splat formation during plasma spraying," Surface and Coatings Technology, vol. 184, no. 1, pp. 13-23, 2004.

[23] C. J. Li, C. X. Li, G. J. Yang, and Y. Y. Wang, "Examination of substrate surface melting-induced splashing during splat formation in plasma spraying," Journal of Thermal Spray Technology, vol. 15, no. 4, pp. 717-724, 2006.

[24] M. Fukumoto, E. Nishioka, and T. Matsubara, "Flattening and solidification behavior of a metal droplet on a flat substrate surface held at various temperatures," Surface and Coatings Technology, vol. 120-121, pp. 131-137, 1999.

[25] M. Fukumoto, K. Yang, K. Tanaka, T. Usami, T. Yasui, and M. Yamada, "Effect of substrate temperature and ambient pressure on heat transfer at interface between molten droplet and substrate surface," Journal of Thermal Spray Technology, vol. 20, no. 1-2, pp. 48-58, 2011.

[26] L. Bianchi, A. Grimaud, F. Blein, P. Lucchese, and P. Fauchais, "Comparison of plasma-sprayed alumina coatings by RF and DC plasma spraying," Journal of Thermal Spray Technology, vol. 4, no. 1, pp. 59-66, 1995.

[27] M. Vardelle, A. Vardelle, A. C. Leger, P. Fauchais, and D. Gobin, "Influence of particle parameters at impact on splat formation and solidification in plasma spraying processes," Journal of Thermal Spray Technology, vol. 4, no. 1, pp. 50-58, 1995.

[28] J. M. Houben, "Future development in thermal spraying," in Proceedings of the 2nd National Conference on Thermal Spray, pp. 1-19, 1984.

[29] S. Brunauer, P. H. Emmett, and E. Teller, "Adsorption of gases in multimolecular layers," Journal of the American Chemical Society, vol. 60, no. 2, pp. 309-319, 1938.

[30] A. McDonald, M. Lamontagne, C. Moreau, and S. Chandra, "Impact of plasma-sprayed metal particles on hot and cold glass surfaces," Thin Solid Films, vol. 514, no. 1-2, pp. 212-222, 2006.

[31] X. Jiang, Y. Wan, H. Herman, and S. Sampath, "Role of condensates and adsorbates on substrate surface on fragmentation of impinging molten droplets during thermal spray," Thin Solid Films, vol. 385, no. 1-2, pp. 132-141, 2001.

[32] I. A. Polunina, A. A. Isirikyan, K. E. Polounine, and S. S. Mikhailova, "Water influence on the surfactant adsorption on $\mathrm{TiO}_{2}$," Colloids and Surfaces A, vol. 160, no. 2, pp. 141-146, 1999.

[33] M. Fukumoto, H. Nagai, and T. Yasui, "Influence of surface character change of substrate due to heating on flattening behavior of thermal sprayed particles," Journal of Thermal Spray Technology, vol. 15, no. 4, pp. 759-764, 2006.

[34] J. Cedelle, M. Vardelle, and P. Fauchais, "Influence of stainless steel substrate preheating on surface topography and on millimeter- and micrometer-sized splat formation," Surface and Coatings Technology, vol. 201, no. 3-4, pp. 1373-1382, 2006.

[35] M. Fukumoto, I. Ohgitani, M. Shiiba, and T. Yasui, "Effect of substrate surface change by heating on transition in flattening behavior of thermal sprayed particles," in Proceedings of the International Thermal Spray Conference, pp. 246-251, May 2004.
[36] M. Fukumoto, I. Ohgitani, H. Nagai, and T. Yasui, "Effect of substrate surface change by heating on flattening behavior of thermal sprayed particles," in Proceedings of the International Thermal Spraying Conference, 2005.

[37] Y. Heichal and S. Chandra, "Predicting thermal contact resistance between molten metal droplets and a solid surface," Journal of Heat Transfer, vol. 127, no. 11, pp. 1269-1275, 2005.

[38] A. McDonald, C. Moreau, and S. Chandra, "Thermal contact resistance between plasma-sprayed particles and flat surfaces," International Journal of Heat and Mass Transfer, vol. 50, no. 910, pp. 1737-1749, 2007.

[39] A. McDonald, C. Moreau, and S. Chandra, "Effect of substrate oxidation on spreading of plasma-sprayed nickel on stainless steel," Surface and Coatings Technology, vol. 202, no. 1, pp. 23-33, 2007.

[40] R. Dhiman, A. G. McDonald, and S. Chandra, "Predicting splat morphology in a thermal spray process," Surface and Coatings Technology, vol. 201, no. 18, pp. 7789-7801, 2007.

[41] D. K. Christoulis, D. I. Pantelis, N. de Dave-Fabrègue, F. Borit, V. Guipont, and M. Jeandin, "Effect of substrate temperature and roughness on the solidification of copper plasma sprayed droplets," Materials Science and Engineering A, vol. 485, no. 1-2, pp. 119-129, 2008.

[42] S. Costil, H. Liao, A. Gammoudi, and C. Coddet, "Influence of surface laser cleaning combined with substrate preheating on the splat morphology," Journal of Thermal Spray Technology, vol. 14, no. 1, pp. 31-38, 2005.

[43] M. F. Morks, Y. Tsunekawa, M. Okumiya, and M. A. Shoeib, "Splat morphology and microstructure of plasma sprayed cast iron with different preheat substrate temperatures," Journal of Thermal Spray Technology, vol. 11, no. 2, pp. 226-232, 2002.

[44] H. R. Salimijazi, L. Pershin, T. W. Coyle et al., "Effect of droplet characteristics and substrate surface topography on the final morphology of plasma-sprayed zirconia single splats," Journal of Thermal Spray Technology, vol. 16, no. 2, pp. 291-299, 2007.

[45] R. N. Wenzel, "Resistance of solid surfaces to wetting by water," Industrial and Engineering Chemistry, vol. 28, no. 8, pp. 988-994, 1936.

[46] T. Uelzen and J. Müller, "Wettability enhancement by rough surfaces generated by thin film technology," Thin Solid Films, vol. 434, no. 1-2, pp. 311-315, 2003.

[47] V. Pershin, M. Lufitha, S. Chandra, and J. Mostaghimi, "Effect of substrate temperature on adhesion strength of plasma-sprayed nickel coatings," Journal of Thermal Spray Technology, vol. 12, no. 3, pp. 370-376, 2003.

[48] K. Yang, K. Tomita, M. Fukumoto, M. Yamada, and T. Yasui, "Effect of ambient pressure on flattening behavior of thermal sprayed particles," Journal of Thermal Spray Technology, vol. 18, no. 4, pp. 510-518, 2009.

[49] K. Yang, K. Tanaka, T. Usami, and M. Fukumoto, "Role of ambient pressure on splat formation and coating adhesion strength during thermal spraying process," Quarterly Journal of the Japan Welding Society, vol. 29, no. 3, pp. 151s-155s, 2011.

[50] M. F. Morks, Y. Tsunekawa, M. Okumiya, and M. A. Shoeib, "Splat microstructure of plasma sprayed cast iron with different chamber pressures," Journal of Thermal Spray Technology, vol. 12, no. 2, pp. 282-289, 2003.

[51] K. Yang, Y. Ebisuno, K. Tanaka, M. Fukumoto, T. Yasui, and M. Yamada, "Verification of the flattening behavior of thermalsprayed particles and free-falling droplets through controlling ambient pressure," Surface and Coatings Technology, vol. 205, no. 13-14, pp. 3816-3823, 2011. 
[52] S. Brossard, P. R. Munroe, A. T. T. Tran, and M. M. Hyland, "Study of the effects of surface chemistry on splat formation for plasma sprayed NiCr onto stainless steel substrates," Surface and Coatings Technology, vol. 204, no. 9-10, pp. 1599-1607, 2010.

[53] S. Chandra and P. Fauchais, "Formation of solid splats during thermal spray deposition," Journal of Thermal Spray Technology, vol. 18, no. 2, pp. 148-180, 2009.

[54] Y. Z. Xing and C. J. Li, "Bonding characteristics of a plasmasprayed Yttria-stabilized zirconia splat on a high-temperature substrate," in Proceedings of the 4th Asian Thermal Spray Conference, pp. 285-288, 2009.

[55] P. Fauchais, "Understanding plasma spraying," Journal of Physics D, vol. 37, no. 9, pp. R86-R108, 2004.

[56] M. Dorfman, “Thermal spray basics," Advanced Materials and Processes, vol. 160, pp. 47-50, 2002.

[57] G. Montavon, S. Sampath, C. C. Berndt, H. Herman, and C. Coddet, "Effects of vacuum plasma spray processing parameters on splat morphology," Journal of Thermal Spray Technology, vol. 4, no. 1, pp. 67-74, 1995.

[58] L. Li, A. Vaidya, S. Sampath, H. Xiong, and L. Zheng, "Particle characterization and splat formation of plasma sprayed zirconia," Journal of Thermal Spray Technology, vol. 15, no. 1, pp. 97-105, 2006.

[59] M. Fukumoto, E. Nishioka, and T. Nishiyama, "The criterion for splashing in flattening of thermal sprayed particles onto flat substrate surface," Surface and Coatings Technology, vol. 161, no. 2-3, pp. 103-110, 2002.

[60] M. Fukumoto, T. Yamaguchi, M. Yamada, and T. Yasui, "Splash splat to disk splat transition behavior in plasma-sprayed metallic materials," Journal of Thermal Spray Technology, vol. 16, no. 5-6, pp. 905-912, 2007.

[61] C. J. Li, J. L. Li, W. B. Wang, A. Ohmori, and K. Tani, "Effect of particle-substrate materials combinations on morphology of plasma sprayed splats," in Proceedings of the 15th International Thermal Spray Conference, pp. 481-487, May 1998.

[62] Y. Tanaka and M. Fukumoto, "Investigation of dominating factors on flattening behavior of plasma sprayed ceramic particles," Surface and Coatings Technology, vol. 120-121, pp. 124-130, 1999.

[63] M. Fukumoto, S. Kato, M. Ohwatari, and Y. Huang, "Splatting and solidification behavior of plasma sprayed metallic powders impinging on flat SUS304 substrate," Journal of the Japan Institute of Metals, vol. 59, pp. 1178-1184, 1995.

[64] Y. Tanaka and M. Fukumoto, "Dominant factor in the behavior of a particular flat ceramic-coated particles," Quarterly Journal of the Japan Welding Society, vol. 17, no. 2, pp. 259-265, 1999 (Japanese).

[65] M. Fukumoto and Y. Huang, "Flattening mechanism in thermal sprayed nickel particle impinging on flat substrate surface," Journal of Thermal Spray Technology, vol. 8, no. 3, pp. 427-432, 1999.

[66] Y. Tanaka and M. Fukumoto, "Effects of solidification and wetting on flattening behavior of thermal sprayed ceramic particles," Quarterly Journal of the Japan Welding Society, vol. 18, no. 1, pp. 26-32, 2000 (Japanese).

[67] Y. Huang, M. Ohwatari, and M. Fukumoto, "Effect of substrate material on flattening behavior of plasma sprayed Ni particles," in Proceedings of the 6th International Symposium, pp. 731-736, JWS, 1996 (Japanese).

[68] Y. Huang, M. Ohwatari, and M. Fukumoto, "Flattening behavior of plasma sprayed Ni particles on various substrate materials,"
Journal of the Japan Institute of Metals, vol. 60, no. 12, pp. 1215-1221, 1996 (Japanese).

[69] M. F. Bahbou and P. Nylén, "On-line measurement of plasmasprayed Ni-particles during impact on a Ti-surface: influence of surface oxidation," Journal of Thermal Spray Technology, vol. 16, no. 4, pp. 506-511, 2007.

[70] M. Fukumoto, I. Ohgitani, and T. Yasui, "Effect of substrate surface change on flattening behaviour of thermal sprayed particles," Materials Transactions, vol. 45, no. 6, pp. 1869-1873, 2004.

[71] S. Amada, K. Imagawa, and S. Aoki, "Splat profile of impinging droplets on rough substrates: influence of surface roughness," Surface and Coatings Technology, vol. 154, no. 1, pp. 27-33, 2002.

[72] M. Qu and A. Gouldstone, "On the role of bubbles in metallic splat nanopores and adhesion," Journal of Thermal Spray Technology, vol. 17, no. 4, pp. 486-494, 2008.

[73] C. Moreau, P. Gougeon, and M. Lamontagne, "Influence of substrate preparation on the flattening and cooling of plasmasprayed particles," Journal of Thermal Spray Technology, vol. 4, no. 1, pp. 25-33, 1995.

[74] K. Shinoda, A. Yamada, M. Kambara, Y. Kojima, and T. Yoshida, "Deformation of alumina droplets on micro-patterned substrates under plasma spraying conditions," Journal of Thermal Spray Technology, vol. 16, no. 2, pp. 300-305, 2007.

[75] H. B. Parizi, L. Rosenzweig, J. Mostaghimi et al., "Numerical simulation of droplet impact on patterned surfaces," Journal of Thermal Spray Technology, vol. 16, no. 5-6, pp. 713-721, 2007.

[76] A. McDonald, S. Chandra, and C. Moreau, "Photographing impact of plasma-sprayed particles on rough substrates," Journal of Materials Science, vol. 43, no. 13, pp. 4631-4643, 2008.

[77] C. J. Li, J. L. Li, and W. B. Wang, "The effect of substrate preheating and surface organic covering on splat formation," in Proceedings of the 15th International Thermal Spray Conference, pp. 473-480, May 1998.

[78] A. T. T. Tran, Effect of surface chemistry on splat formation during plasma spraying [Ph.D. thesis], University of Auckland, 2010.

[79] A. T. T. Tran and M. M. Hyland, "The role of substrate surface chemistry on splat formation during plasma spray deposition by experiments and simulations," Journal of Thermal Spray Technology, vol. 19, no. 1-2, pp. 11-23, 2010.

[80] A. T. T. Tran, M. M. Hyland, T. Qiu, B. Withy, and B. J. James, "Effects of surface chemistry on splat formation during plasma spraying," Journal of Thermal Spray Technology, vol. 17, no. 5-6, pp. 637-645, 2008.

[81] Y. Tanaka and M. Fukumoto, "Influence of solidification and wetting on flattening behavior of plasma sprayed ceramic particles," International Journal of Materials and Product Technology, vol. 1, pp. 518-523, 2001.

[82] H. Li, S. Costil, H. L. Liao, and C. Coddet, "Role of the laser surface preparation on the adhesion of $\mathrm{Ni}-5 \% \mathrm{Al}$ coatings deposited using the PROTAL process," Journal of Thermal Spray Technology, vol. 15, no. 2, pp. 191-197, 2006.

[83] E. G. Shafrin and W. A. Zisman, "Constitutive relations in the wetting of low energy surfaces and the theory of the retraction method of preparing monolayers," Journal of Physical Chemistry, vol. 64, no. 5, pp. 519-524, 1960.

[84] K. Suganuma, "Interfacial bond strength and interfacial energy metal-ceramic," Bulletin of the Japan Institute of Metals, vol. 29, no. 11, pp. 882-887, 1990 (Japanese). 
[85] K. Nogi, N. Iwamoto, and K. Ogin, "Mechanism of wetting of ceramics by molten metal," Bulletin of the Japan Institute of Metals, vol. 31, no. 4, pp. 278-281, 1992 (Japanese).

[86] K. Yang, M. Fukumoto, T. Yasui, and M. Yamada, "Role of substrate temperature on microstructure formation in plasmasprayed splats," Surface and Coatings Technology, vol. 214, no. 1, pp. 138-143, 2013.

[87] T. Chraskaa and A. H. King, "Effect of different substrate conditions upon interface with plasma sprayed zirconia-a TEM study," Surface and Coatings Technology, vol. 157, no. 23, pp. 238-246, 2002.

[88] T. Chraskaa and A. H. King, "Transmission electron microscopy study of rapid solidification of plasma sprayed zirconia-part II. Interfaces and subsequent splat solidification," Thin Solid Films, vol. 397, no. 1-2, pp. 40-48, 2001.

[89] H. Li, K. A. Khor, and P. Cheang, "Thermal sprayed hydroxyapatite splats: nanostructures, pore formation mechanisms and TEM characterization," Biomaterials, vol. 25, no. 17, pp. 3463-3471, 2004.

[90] A. T. T. Tran, M. M. Hyland, K. Shinoda, and S. Sampath, "Influence of substrate surface conditions on the deposition and spreading of molten droplets," Thin Solid Films, vol. 519, no. 8, pp. 2445-2456, 2011.

[91] M. Ivosevic, R. A. Cairncross, and R. Knight, “3D predictions of thermally sprayed polymer splats: modeling particle acceleration, heating and deformation on impact with a flat substrate," International Journal of Heat and Mass Transfer, vol. 49, no. 1920, pp. 3285-3297, 2006.

[92] F. H. Harlow and J. P. Shannon, "The splash of a liquid drop," Journal of Applied Physics, vol. 38, no. 10, pp. 3855-3866, 1967.

[93] J. Madjeski, "Solidification of droplets on a cold surface," International Journal of Heat and Mass Transfer, vol. 19, no. 9, pp. 1009-1013, 1976.

[94] V. V. Sobolev and J. M. Guilemany, "Flattening of droplets and formation of splats in thermal spraying: a review of recent work-part 1," Journal of Thermal Spray Technology, vol. 8, no. 1, pp. 87-101, 1999.

[95] V. V. Sobolev and J. M. Guilemany, "Effect of oxidation on droplet flattening and splat-substrate interaction in thermal spraying," Journal of Thermal Spray Technology, vol. 8, no. 4, pp. 523-530, 1999.

[96] V. V. Sobolev and J. M. Guilemany, "Effect of substrate deformation on droplet flattening in thermal spraying," Materials Letters, vol. 35, no. 5-6, pp. 324-328, 1998.

[97] V. V. Sobolev and J. M. Guilemany, "Effect of wave processes on splat formation during thermal spraying," Materials Letters, vol. 42 , no. 5, pp. 321-325, 2000.

[98] V. V. Sobolev, "Formation of splat morphology during thermal spraying," Materials Letters, vol. 36, no. 1-4, pp. 123-127, 1998.

[99] V. V. Sobolev and J. M. Guilemany, "Formation of splats during thermal spraying of composite powder particles," Materials Letters, vol. 42, no. 1-2, pp. 46-51, 2000.

[100] V. V. Sobolev and J. M. Guilemany, "Influence of wetting and surface effects on splat formation during thermal spraying," Materials Letters, vol. 37, no. 3, pp. 132-137, 1998.

[101] H. Zhang, X. Y. Wang, L. L. Zheng, and S. Sampath, "Numerical simulation of nucleation, solidification, and microstructure formation in thermal spraying," International Journal of Heat and Mass Transfer, vol. 47, no. 10-11, pp. 2191-2203, 2004.

[102] X. Y. Wang, H. Zhang, L. L. Zheng, and S. Sampath, "An integrated model for interaction between melt flow and nonequilibrium solidification in thermal spraying," International
Journal of Heat and Mass Transfer, vol. 45, no. 11, pp. 2289-2301, 2002.

[103] H. Fukanuma, "Porosity formation and flattening model of an impinging molten particle in thermal spray coatings," Journal of Thermal Spray Technology, vol. 3, no. 1, pp. 33-44, 1994.

[104] J. Shimizu, E. Ohmura, Y. Kobayashi, S. Kiyoshima, and H. Eda, "Molecular dynamics simulation of flattening process of a high-temperature, high-speed droplet-influence of impact parameters," Journal of Thermal Spray Technology, vol. 16, no. 5-6, pp. 722-728, 2007.

[105] C. W. Kang, H. W. Ng, and S. C. M. Yu, "Plasma spray deposition on inclined substrates: simulations and experiments," Journal of Thermal Spray Technology, vol. 16, no. 2, pp. 261-274, 2007.

[106] M. Ivosevic, V. Gupta, J. A. Baldoni, R. A. Cairncross, T. E. Twardowski, and R. Knight, "Effect of substrate roughness on splatting behavior of HVOF sprayed polymer particles: modeling and experiments," Journal of Thermal Spray Technology, vol. 15, no. 4, pp. 725-730, 2006.

[107] M. Pasandideh-Fard, V. Pershin, S. Chandra, and J. Mostaghimi, "Splat shapes in a thermal spray coating process: simulations and experiments," Journal of Thermal Spray Technology, vol. 11, no. 2, pp. 206-217, 2002.

[108] A. V. Kiselev and A. V. Uvarov, "Infrared spectra and electron spin resonance of aluminium, silicon and titanium oxides and of adsorbed substances," Surface Science, vol. 6, no. 4, pp. 399-421, 1967.

[109] S. Kitahara and A. Hasui, "A study of the bonding mechanism of sprayed coatings," Journal of Vacuum Science \& Technology, vol. 11, no. 4, pp. 747-753, 1974.

[110] H. D. Steffens, B. Wielage, and J. Drozak, "Interface phenomena and bonding mechanism of thermally-sprayed metal and ceramic composites," Surface and Coatings Technology, vol. 45, no. 1-3, pp. 299-308, 1991.

[111] S. Brossard, P. R. Munroe, A. Tran, and M. M. Hyland, "Study of the splat-substrate interface for a $\mathrm{NiCr}$ coating plasma sprayed onto polished aluminum and stainless steel substrates," Journal of Thermal Spray Technology, vol. 19, no. 1-2, pp. 24-30, 2010.

[112] S. Brossard, P. R. Munroe, A. T. T. Tran, and M. M. Hyland, "Study of the microstructure of NiCr splats plasma sprayed on to stainless steel substrates by TEM," Surface and Coatings Technology, vol. 204, no. 9-10, pp. 1608-1615, 2010.

[113] A. T. T. Tran, S. Brossard, M. M. Hyland, B. J. James, and P. Munroe, "Evidence of substrate melting of NiCr particles on stainless steel substrate by experimental observation and simulations," Plasma Chemistry and Plasma Processing, vol. 29, no. 6, pp. 475-495, 2009.

[114] C. Mundo, M. Sommerfeld, and C. Tropea, "Droplet-wall collisions: experimental studies of the deformation and breakup process," International Journal of Multiphase Flow, vol. 21, no. 2, pp. 151-173, 1995.

[115] P. Fauchais, M. Fukumoto, A. Vardelle, and M. Vardelle, "Knowledge concerning splat formation: an invited review," Journal of Thermal Spray Technology, vol. 13, no. 3, pp. 337-360, 2004.

[116] C. Escure, M. Vardelle, A. Vardelle, and P. Fauchais, "Visualization of the impact of drops on a substrate in plasma spraying: deposition and splashing modes," in Proceedings of the International Thremal Spray Conferences, pp. 805-812, May 2001.

[117] H. Li, S. Costil, H. L. Liao, C. J. Li, M. Planche, and C. Coddet, "Effects of surface conditions on the flattening behavior of 
plasma sprayed Cu splats," Surface and Coatings Technology, vol. 200, no. 18-19, pp. 5435-5446, 2006.

[118] E. Nishioka, Study on active control method for thermal plasma spray process [Ph.D. thesis], Toyohashi University of Technology, 2001.

[119] A. McDonald, M. Xue, S. Chandra, J. Mostaghimi, and C. Moreau, "Modeling fragmentation of plasma-sprayed particles impacting on a solid surface at room temperature," Comptes Rendus-Mecanique, vol. 335, no. 5-6, pp. 351-356, 2007.

[120] S. D. Aziz and S. Chandra, "Impact, recoil and splashing of molten metal droplets," International Journal of Heat and Mass Transfer, vol. 43, no. 16, pp. 2841-2857, 2000.

[121] Y. Tanaka, S. Yoshida, and R. Kawase, "Effect of impact velocity and preheated substrate temperature on flattening and solidifying behavior of free falling metal droplet," Journal of Japan Thermal Spray Society, vol. 47, pp. 54-60, 2010.

[122] Y. Heichal, S. Chandra, and E. Bordatchev, "A fast-response thin film thermocouple to measure rapid surface temperature changes," Experimental Thermal and Fluid Science Journal, vol. 30, no. 2, pp. 153-159, 2005.

[123] M. Pasandideh-Fard, S. Chandra, and J. Mostaghimi, "A threedimensional model of droplet impact and solidification," International Journal of Heat and Mass Transfer, vol. 45, no. 11, pp. 2229-2242, 2002.

[124] R. G. Azar, Z. Yang, S. Chandra, and J. Mostaghimi, "Impact of molten metal droplets on the tip of a pin projecting from a flat surface," International Journal of Heat and Fluid Flow, vol. 26, no. 2, pp. 334-347, 2005.

[125] M. Pasandideh-Fard, R. Bhola, S. Chandra, and J. Mostaghimi, "Deposition of tin droplets on a steel plate: simulations and experiments," International Journal of Heat and Mass Transfer, vol. 41, no. 19, pp. 2929-2945, 1998.

[126] R. H. S. Winterton, "Newton's law of cooling," Contemporary Physics, vol. 40, no. 3, pp. 205-212, 1999. 

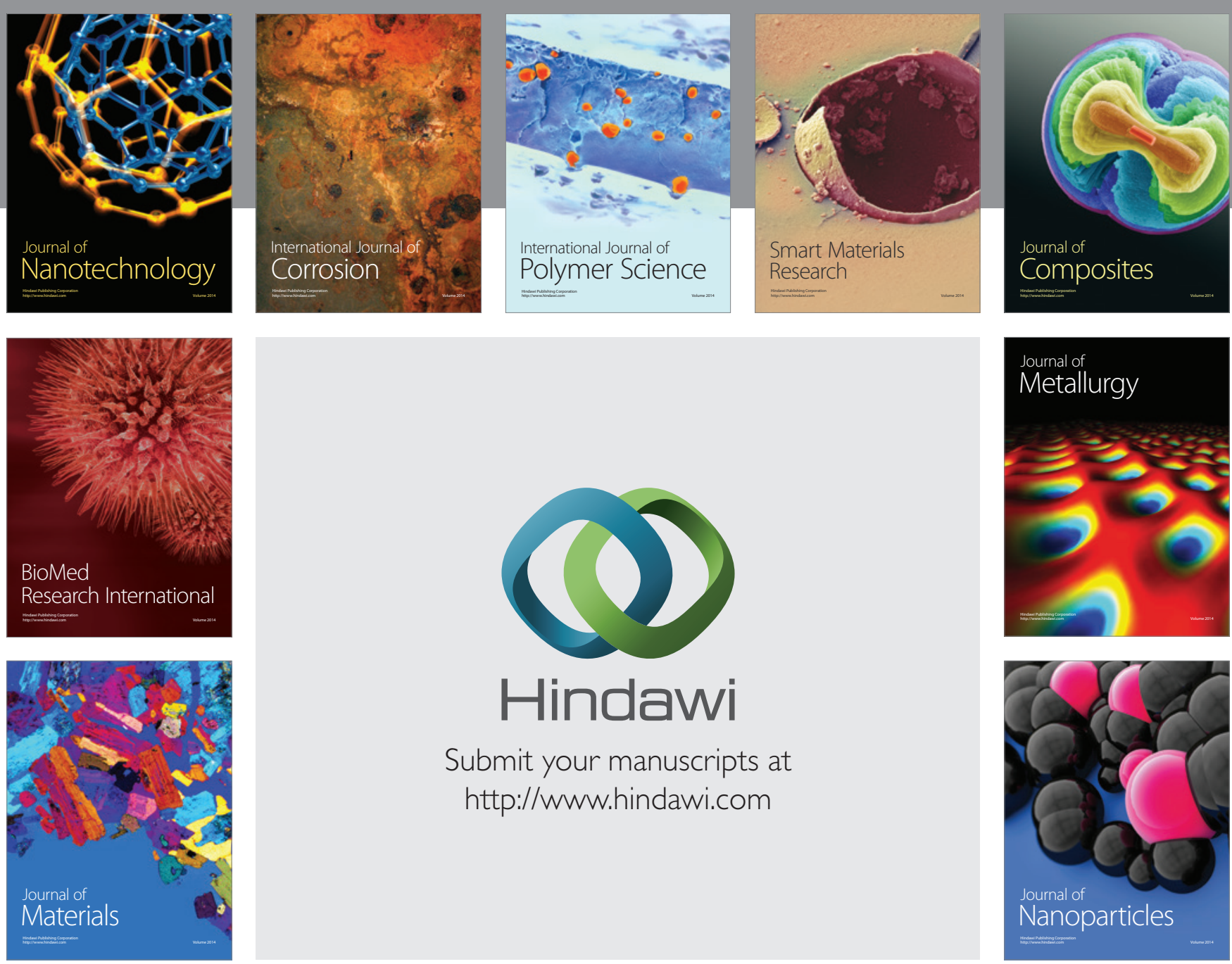

Submit your manuscripts at http://www.hindawi.com
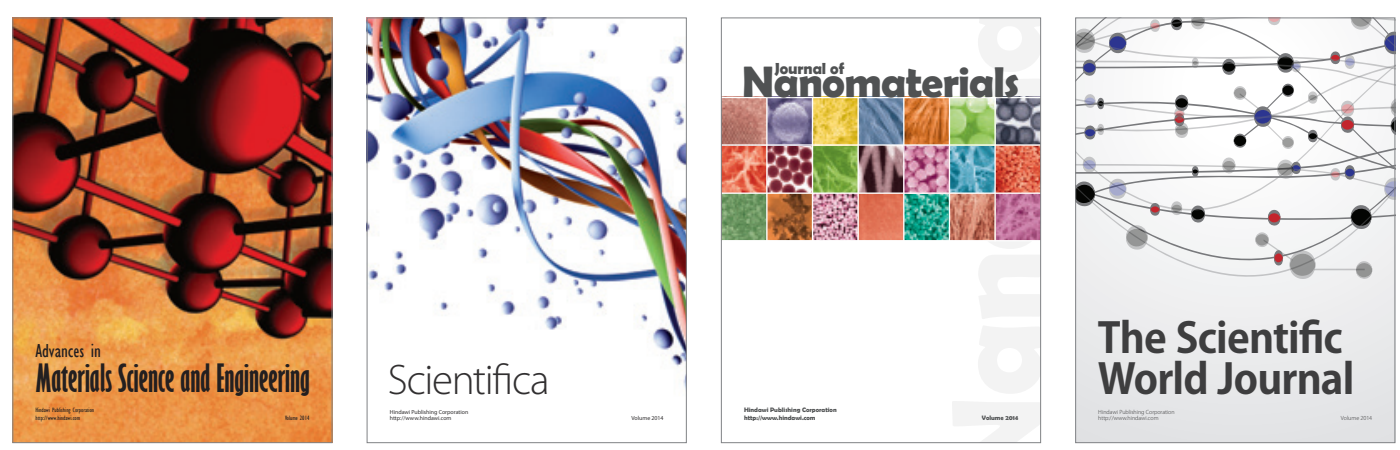

\section{The Scientific World Journal}
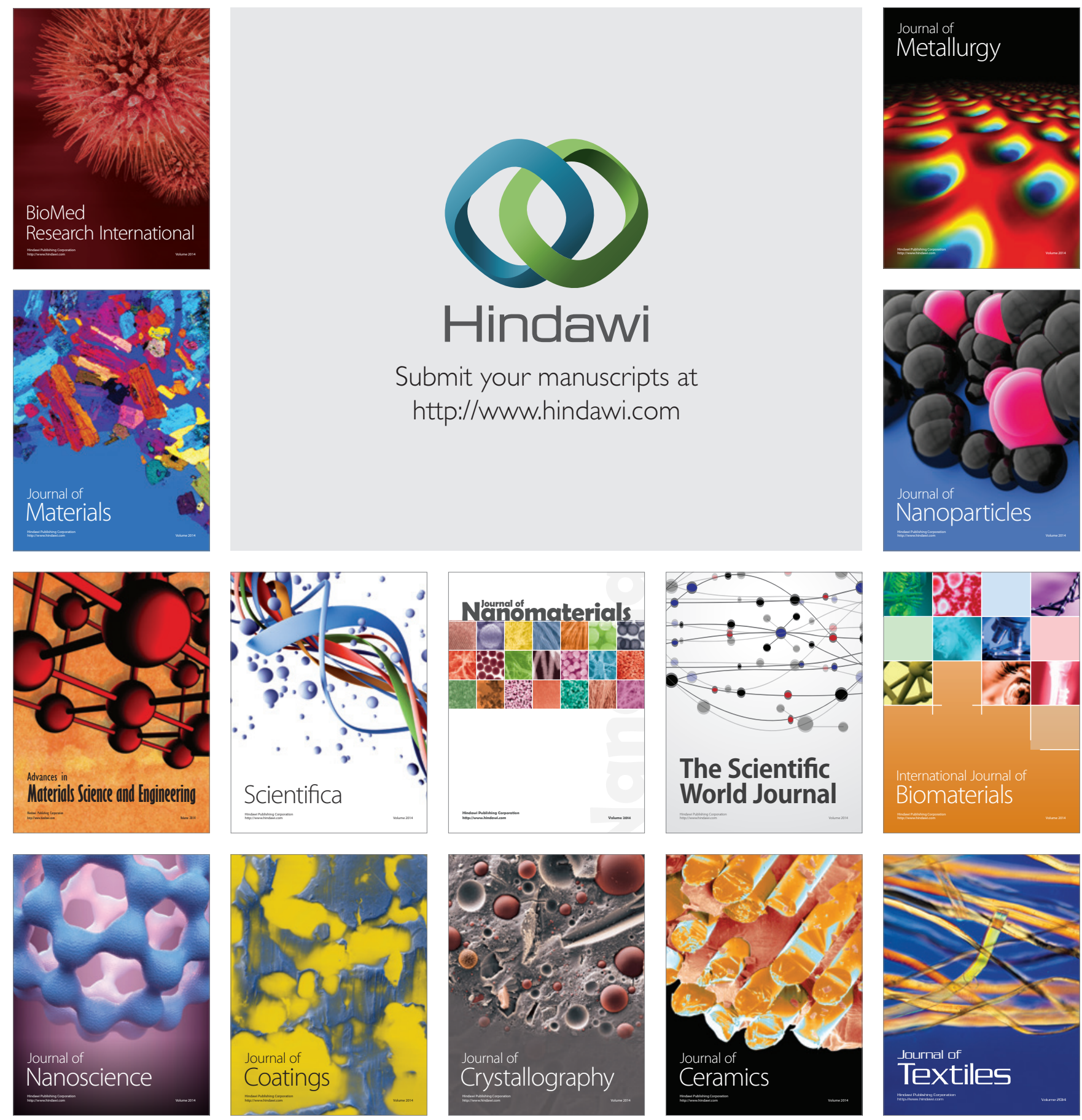